\title{
Uptake Rate of Risk-reducing Salpingo-oophorectomy and Surgical Outcomes of Female Germline BRCA1/2 Mutation Carriers: A Retrospective Cohort Study at a Tertiary Institutional Hospital in Korea
}

Hyunji Lim

Seoul National University College of Medicine

Se lk Kim

Seoul National University College of Medicine

Sowoon Hyun

Seoul National University College of Medicine

Gwang Bin Lee

Seoul National University College of Medicine

Aeran Seol

Seoul National University College of Medicine

Maria Lee ( $\square$ marialeemd@gmail.com)

Seoul National University College of Medicine

Research

Keywords: ovarian cancer, hereditary breast and ovarian cancer syndrome, BRCA gene mutation, risk-reducing salpingo-oophorectomy, RRSO, uptake rate

Posted Date: July 8th, 2021

DOI: https://doi.org/10.21203/rs.3.rs-678142/v1

License: () (1) This work is licensed under a Creative Commons Attribution 4.0 International License. Read Full License 


\section{Abstract}

Background: This study investigated the uptake rate of risk-reducing salpingo-oophorectomy (RRSO) and surgical outcomes of germline $B R C A 1 / 2$ mutation carriers at Seoul National University Hospital (SNUH). We examined records of 824 women who underwent germline BRCA1/2 gene testing at SNUH between 2005 and 2020. Among them, we identified women with a pathogenic mutation on either the BRCA1 or the BRCA2 gene and excluded ovarian cancer patients. Characteristics of participants who underwent RRSO (RRSO group) were compared to those who did not (non-RRSO group). Surgical outcomes and pathologic results were investigated in the RRSO group.

Results: There were 117 BRCA1/2 mutation carriers included in this analysis. The uptake rate of RRSO was 70.1\% (82/117). Older age (mean: 48.8 vs. 42.1 years; $P=0.002)$ and higher employment rate $(65.9 \%$ vs. $14.3 \% ; P<0.001)$ were observed in the RRSO group than in the non-RRSO group. However, no differences in other factors such as personal and family history of breast cancer were observed between the two groups. In the RRSO group, the median time interval between the genetic test and RRSO was 10.0 months, and there were three (3.7\%) incidental cases of high-grade serous carcinoma. However, one patient in the non-RRSO group developed primary peritoneal cancer after 103.8 months of surveillance.

Conclusions: The uptake rate of RRSO in BRCA1/2 mutation carriers was about 70\%. Considering incidental cancer cases in women without abnormal findings on preoperative evaluation, it would be recommended to perform RRSO soon after the genetic test.

\section{Background}

Ovarian cancer, one of the most lethal gynaecological malignancies, is a global burden, with 313,959 new cases and 207,252 deaths estimated in 2020 (1). Due to a lack of appropriate screening tools for ovarian cancer, most patients are diagnosed at an advanced stage. Accordingly, the prognosis of ovarian cancer is poor-the likelihood of 5 -year survival is $23 \%$ in stage III and only $11 \%$ in stage IV. Many efforts have been focused on diagnosing ovarian cancer at an early stage through risk prediction and prevention. Identifying genetic predisposition offers opportunities for cancer prevention.

The BRCA1 and BRCA2 genes are the most commonly mutated genes in ovarian cancer patients. These autosomal dominant mutations account for approximately $90 \%$ of hereditary ovarian cancers and $30-70 \%$ of hereditary breast cancers (2). People with these genetic mutations have a higher chance of developing breast and ovarian cancer. The cumulative risk of breast cancer at age 70 is $45-85 \%$ in individuals with the $B R C A 1 / 2$ gene mutation compared to the $11 \%$ risk of the general population. In addition, the cumulative risk of ovarian cancer at age 70 is $39-46 \%$ for the $B R C A 1$ mutation and $10-27 \%$ for the BRCA2 mutation, compared to the $1.3 \%-1.9 \%$ risk of the general population (3) (4). These cancers develop 10 years earlier than non-hereditary cancers, and the most common histologic type in ovarian cancer is high-grade serous carcinoma (HGSC).

Risk-reducing salpingo-oophorectomy (RRSO) is currently regarded as one of the most protective tools for $B R C A 1 / 2$ mutation carriers. Typically, RRSO is recommended between the ages of 35 and 40 for the BRCA1 mutation, between ages 40 and 45 for the BRCA2 mutation, and upon completion of childbearing (5). Otherwise, intensive screening for ovarian cancer is recommended: transvaginal ultrasonography combined with serum CA-125 may be considered from age 30 to 35, although benefits of this are uncertain. It is known that there are many factors that affect patients' decisions to undergo RRSO, such as personal or family history of breast cancer, individual family plan, social atmosphere, and so on.

At our hospital, the BRCA1/2 gene tests on high-risk patients have been conducted since 2005. This study presents a 15-year experience of RRSO in female germline $B R C A 1 / 2$ mutation carriers at a tertiary institutional hospital in Korea. We also investigated significant factors that might affect the carriers' decisions.

\section{Materials And Methods Study population}

Between September 2005 and August 2020, a total of 824 women underwent germline BRCA1/2 gene testing at our institution. We included women aged 20 or older who had a pathogenic or a likely pathogenic variant on either the BRCA1 or the BRCA2 gene. We excluded women with the following conditions: (1) those diagnosed with peritoneal, ovarian, or tubal cancers, or received bilateral salpingo-oophorectomy before the time of the genetic test; (2) had not been referred to the OB/GYN clinic; or (3) were lost to follow-up checks after visiting the OB/GYN clinic once.

Overall, 117 BRCA1/2 mutation carriers who met these inclusion criteria were included in this analysis (Fig. 1). They were divided into two groups based on whether they received RRSO after BRCA1/2 gene testing or not. Thereafter, we compared the baseline characteristics of the RRSO and non-RRSO (surveillance only) groups.

\section{Data collection}

We reviewed the women's medical records and pathologic reports, retrospectively, and collected their clinicopathologic data, including age at $B R C A 1 / 2$ gene testing, menopausal status, parity, marital status, educational status, occupational status, comorbidity, prior abdominopelvic surgery, and personal history of breast and other cancers. Family history of breast, ovarian, and other cancers were also collected up to the women's second-degree relatives. Germline $B R C A 1 / 2$ gene testing methods at SNUH were described in our previous study (6). As of February 2016, the method changed from direct sequencing (Sanger sequencing) to next-generation sequencing (NGS) of BRCA1/2 genes. Pathogenic or like-pathogenic variants found in NGS were confirmed by direct sequencing. 
In the non-RRSO group, patients received regular examinations with transvaginal ultrasonography, serum CA-125, or both every 6-12 months. In the RRSO group, the patients also received regular examinations until the date of RRSO, and we collected their detailed surgical information and pathological results. Observation period was defined as intervals between the BRCA1/2 gene test and date of gynecologic cancer diagnosis or last visit in the non-RRSO group, while it was defined as intervals between the BRCA gene test and date of RRSO in the RRSO group.

Statistical analysis

First, we calculated the total uptake rate of RRSO in BRCA1/2 mutation carriers. Next, regarding $B R C A 1 / 2$ mutation carriers aged $\geq 35$ years at the time of genetic testing and receiving RRSO within 12 months as having intentions to receive RRSO, we assigned them to the RRSO strategy group. In contrast, the remaining participants were assigned to the surveillance strategy group. We calculated the intentional uptake rate of RRSO, which was the proportion of patients receiving RRSO within a year among BRCA1/2 mutated patients aged $\geq 35$.

We compared women's clinicopathologic characteristics between the two groups using Student's t- or Mann-Whitney U-tests for continuous variables and Pearson's chi-squared or Fisher's exact tests for categorical variables. In multivariate analysis, we used a logistic regression model to calculate adjusted odds ratio (aOR) and 95\% confidence interval (Cl) for each variable. All these statistical analyses were performed using SPSS statistical software (version 25.0; IBM Corp., Armonk, NY, USA). A $P$ value of less than 0.05 was considered statistically significant.

\section{Results}

During 18.8 months of the median observation periods, 82 of the 117 BRCA1/2 mutation carriers received RRSO; therefore, the total uptake rate of RRSO was calculated as $70.1 \%$. The women's characteristics at the time of the BRCA1/2 gene test are shown in Table 1 . Women in the RRSO group were significantly $\operatorname{older}(P=0.002)$ and had higher employment rate $(P<0.001)$, compared to those in the non-RRSO group. However, other characteristics, such as parity, comorbidity, menopausal and educational status, prior abdominopelvic surgery, type of mutated gene (BRCA1 or BRCA2), personal history of cancer other than breast/ovarian cancers, and family history of cancers, were similar between the two groups. 
Table 1

Characteristics of the study population at the time of the BRCA1/2 gene test

\begin{tabular}{|c|c|c|c|c|}
\hline Characteristics & $\begin{array}{l}\text { All } \\
(n=117, \%)\end{array}$ & $\begin{array}{l}\text { Surveillance only } \\
(n=35, \%)\end{array}$ & $\begin{array}{l}\text { RRSO } \\
(\mathrm{n}=82, \%)\end{array}$ & $P$ \\
\hline Age at $B R C A$ test, years & & & & 0.002 \\
\hline Mean $\pm S D$ & $46.8 \pm 11.2$ & $42.1 \pm 13.0$ & $48.8 \pm 9.8$ & \\
\hline Menopausal status & & & & 0.083 \\
\hline Premenopause & $66(56.4)$ & $24(68.6)$ & $42(51.2)$ & \\
\hline Menopause & $51(43.6)$ & $11(31.4)$ & $40(48.8)$ & \\
\hline Parity & & & & 0.129 \\
\hline Mean \pm SD & $1.7 \pm 1.1$ & $1.5 \pm 1.1$ & $1.8 \pm 1.1$ & \\
\hline Median (range) & $2.0(0-5)$ & $2.0(0-4)$ & $2.0(0-5)$ & \\
\hline Null & $19(16.2)$ & $8(22.9)$ & $11(13.4)$ & 0.205 \\
\hline Marital status & & & & 0.106 \\
\hline Single & $17(14.5)$ & $6(17.1)$ & $11(13.4)$ & \\
\hline Married & $96(82.1)$ & $26(74.3)$ & $70(85.4)$ & \\
\hline Divorced/Bereavement & $4(3.4)$ & $3(8.6)$ & $1(1.2)$ & \\
\hline Educational status & & & & 0.546 \\
\hline$\leq$ High school & $38(32.5)$ & $10(28.6)$ & $28(34.1)$ & \\
\hline$\geq$ College & $50(42.7)$ & $14(40.0)$ & $36(43.9)$ & \\
\hline Unknown & $29(24.8)$ & $11(31.4)$ & $18(22.0)$ & \\
\hline Occupational status & & & & $<0.001$ \\
\hline No & $47(40.2)$ & $22(62.9)$ & $25(30.5)$ & \\
\hline Yes & $59(50.4)$ & $5(14.3)$ & $54(65.9)$ & \\
\hline Unknown & $11(9.4)$ & $8(22.9)$ & $3(3.7)$ & \\
\hline \multicolumn{5}{|l|}{ Comorbidity } \\
\hline Hypertension & $12(10.3)$ & $2(5.7)$ & $10(12.2)$ & 0.506 \\
\hline Diabetes & $9(7.7)$ & $2(5.7)$ & $7(8.5)$ & 0.723 \\
\hline Dyslipidemia & $13(11.1)$ & $2(5.7)$ & $11(13.4)$ & 0.339 \\
\hline Prior abdominopelvic surgery & & & & 0.775 \\
\hline No & $78(66.7)$ & $24(68.6)$ & $54(65.9)$ & \\
\hline Yes & 39 (33.3) & $11(31.4)$ & $28(34.1)$ & \\
\hline $\mathrm{Hx}$ of $\mathrm{BC}$ & $101(86.3)$ & $30(85.7)$ & $71(86.6)$ & $>0.999$ \\
\hline \multicolumn{5}{|l|}{ Age at diagnosis of $\mathrm{BC}$} \\
\hline Mean \pm SD & $44.9 \pm 10.9$ & $41.7 \pm 12.6$ & $46.3 \pm 10.0$ & 0.027 \\
\hline Young-age $\mathrm{BC}^{\dagger}$ & $44(37.6)$ & $17(48.6)$ & $27(32.9)$ & 0.084 \\
\hline Bilateral BC & $20(17.1)$ & $2(5.7)$ & $18(22.0)$ & 0.031 \\
\hline Synchronous & $8(6.8)$ & 0 & $8(9.8)$ & 0.495 \\
\hline Metachronous & $12(10.3)$ & $2(5.7)$ & $10(12.2)$ & \\
\hline Recurrent BC & $14(12.0)$ & $3(8.6)$ & $11(13.4)$ & 0.546 \\
\hline Hx of other cancer & $5(4.3)$ & $2(5.7)$ & $3(3.7)$ & 0.635 \\
\hline Family $\mathrm{Hx}$ of $\mathrm{BC}^{\ddagger}$ & 77 (65.8) & $21(60.0)$ & $56(68.3)$ & 0.387 \\
\hline \multicolumn{5}{|l|}{ No. of relatives } \\
\hline Mean \pm SD & $0.9 \pm 0.9$ & $0.8 \pm 0.8$ & $1.0 \pm 0.9$ & 0.198 \\
\hline
\end{tabular}




\begin{tabular}{|c|c|c|c|c|}
\hline Characteristics & $\begin{array}{l}\text { All } \\
(n=117, \%)\end{array}$ & $\begin{array}{l}\text { Surveillance only } \\
(n=35, \%)\end{array}$ & $\begin{array}{l}\text { RRSO } \\
(\mathrm{n}=82, \%)\end{array}$ & $P$ \\
\hline Family $\mathrm{Hx}$ of ovarian cancer & $27(23.1)$ & $7(20.0)$ & $20(24.4)$ & 0.606 \\
\hline \multicolumn{5}{|l|}{ No. of relatives } \\
\hline Mean \pm SD & $0.3 \pm 0.6$ & $0.2 \pm 0.5$ & $0.3 \pm 0.6$ & 0.565 \\
\hline Family $\mathrm{Hx}$ of other cancer ${ }^{\ddagger}$ & $28(23.9)$ & $5(14.3)$ & $23(28.0)$ & 0.110 \\
\hline \multicolumn{5}{|l|}{ No. of relatives } \\
\hline Mean \pm SD & $0.4 \pm 0.8$ & $0.2 \pm 0.5$ & $0.4 \pm 0.8$ & 0.087 \\
\hline Germline $B R C A$ mutational status & & & & 0.586 \\
\hline BRCA1 mutation & $58(49.6)$ & $16(45.7)$ & $42(51.2)$ & \\
\hline$B R C A 2$ mutation & $59(50.4)$ & $19(54.3)$ & $40(48.8)$ & \\
\hline Both gene mutation & 0 & 0 & 0 & \\
\hline \multicolumn{5}{|c|}{$\begin{array}{l}\text { Abbreviations: BC, breast cancer; } \mathrm{Hx} \text {, history; RRSO, risk-reducing salpingo-oophorectomy; SD, sta } \\
{ }^{\star} \text { Menopause was defined when a woman has missed menstruation for } 12 \text { consecutive months. } \\
{ }^{\dagger} \text { Breast cancer diagnosed before the age of } 40 \text { years. }\end{array}$} \\
\hline
\end{tabular}

Overall, 101 (86.3\%) of the study population had been diagnosed with breast cancer before the genetic test, and this proportion did not differ between the RRSO and non-RRSO groups ( $P>0.999)$ (Table 1). However, the age at breast cancer diagnosis was significantly older in the RRSO group than the non-RRSO group (mean, 46.3 vs. 41.7 years, $P=0.027$ ). Regarding history of breast cancer, significantly more patients in the RRSO group had been diagnosed with bilateral breast cancer $(P=0.031)$, while no differences in the proportions of young-age breast cancer (diagnosed before the age of 40 years $)(P=0.084)$ and recurrent breast cancer cases $(P=0.546)$ were observed between the two groups.

In the RRSO group, the median time interval between the BRCA1/2 gene test and RRSO was 10.0 months. During the observation period, 11 of the 71 (15.5\%) breast cancer patients experienced disease recurrence, while one of the 11 (9.1\%) non-breast cancer patients developed de novo breast cancer (Table 2). Surgical details of the RRSO group are presented in Supplementary Table 1. Of 82 women, $58(70.7 \%)$ received RRSO only, while eight (9.8\%) received RRSO plus hysterectomy. The reasons for hysterectomy were uterine myoma $(n=4)$, adenomyosis $(n=1)$, endometrial hyperplasia $(n=1)$, endometrial polyp $(n=1)$, and cervical intraepithelial neoplasia $3(n=1)$. One postmenopausal woman opted to received hysterectomy without any cause. Breast cancer surgery was conducted on the same day of RRSO in 11 (13.4\%) patients, of which one also received simultaneous risk-reducing mastectomy (RRM). Among the rest, three (3.7\%), one (1.2\%), and one (1.25\%) received RRM, myomectomy, and breast augmentation surgery, respectively, concomitantly with RRSO. In terms of the surgical approach for RRSO, laparoscopic surgery was the dominant method that accounted for $95.1 \%$ of the cases, while open surgery was conducted in $4.9 \%$. 
Table 2

Development of breast and gynecologic cancers after the BRCA $1 / 2$ gene test

Characteristics

Surveillance only

$(n=35, \%)$

\section{RRSO}

$(n=82, \%)$
$10.0(1.1-162.6)$

$71(86.6 \%)$

Observational period, months*

Median (range)

$96.6(2.4-175.9)$

$30(85.7 \%)$

$60(73.2 \%)$

Recurrence of $\mathrm{BC}$

No

Yes

$17(48.6 \%)$

$11(13.4 \%)$

Contralateral breast

$13(37.1 \%)$

4

Other sites

4

Both

Development of ovarian cancer

Development of tubal cancer

Development of peritoneal cancer

Development of other cancer

Baseline no $\mathrm{BC}$

9

0

0

0

1

1 (cervix)

$5(14.3)$

$11(13.4)$

Development of BC

0

Development of ovarian cancer

0

1

$1^{\dagger}$

Abbreviations: BC, breast cancer; RRSO, risk-reducing salpingo-oophorectomy

*Observation period was defined as intervals between the $B R C A$ gene test and date of gynecologic cancer diagnosis or last visit in the surveillance-only group, while it was defined as intervals between the BRCA1/2 gene test and date of RRSO in the RRSO group.

${ }^{\dagger}$ Incidental case (diagnosed after RRSO).

The final pathologic diagnosis was reported with no abnormality in $46.3 \%$ of the salpingo-oophorectomy specimens (Supplementary Table 2 ). Approximately, one-third of patients (31.7\%) were diagnosed with paratubal cysts, and other benign lesions were identified in 18 (22.0\%) patients. Three (3.7\%) patients were incidentally diagnosed with ovarian/tubal cancers; HGSCs were identified in their single ovary $(n=1)$, both ovaries $(n=1)$, and single tube $(n=1)$. All patients underwent subsequent laparoscopic staging operations. Regarding the observation periods of these three incidental ovaria/tubal cancer patients, one received RRSO 1.9 months after BRCA1/2 gene testing, and the other two took 14.3 months and 69.0 months.

In the non-RRSO group, the median observation period was 96.6 months, during which 13 of the 30 (43.3\%) breast cancer patients experienced disease recurrence, while none of the five non-breast cancer patients developed de novo breast cancer. Following BRCA1/2 gene testing, one patient was diagnosed with cervical cancer at 26.3 months and another developed primary peritoneal cancer at 103.8 months (Table 2).

The follow-up of the study population focusing on the development of breast and gynecologic cancers after BRCA1/2 gene testing are depicted in Fig. 2. In addition, details of three incidental ovarian/tubal cancer cases in the RRSO group and newly developed primary peritoneal cancer and cervical cancer cases are shown in Table 3. 
Table 3

Detailed characteristics of patients who developed gynecologic cancers

\begin{tabular}{|c|c|c|c|c|c|c|c|c|c|c|c|}
\hline No. & $\begin{array}{l}\text { Age, } \\
\text { years }\end{array}$ & Mutated gene & Parity/MP & Comorbidity & $\begin{array}{l}\text { Family } \\
\mathrm{Hx} \text { of } \\
\mathrm{BC}\end{array}$ & $\begin{array}{l}\text { Family } \\
\text { Hx of } \\
\text { OC }\end{array}$ & $\begin{array}{l}\text { BC } \\
\text { (age, } \\
\text { years) }\end{array}$ & Strategy & $\begin{array}{l}\text { Time } \\
\text { interval, } \\
\text { months }\end{array}$ & $\begin{array}{l}\text { Preoperative } \\
\text { findings }\end{array}$ & Surgen \\
\hline$\# 1$. & 55.6 & $\begin{array}{l}\text { BRCA2 } \\
\text { c.5722_5723delCT }\end{array}$ & $3 / \mathrm{MP}$ & No & Mother & No & $\begin{array}{l}\text { Yes, } \\
\text { bilateral } \\
(55.6)\end{array}$ & RRSO & 1.9 & $\begin{array}{l}\text { Unilateral } \\
\text { ovarian } \\
\text { cyst, } 3 \mathrm{~cm}\end{array}$ & $\begin{array}{l}\text { SPL } \\
\text { BSO }\end{array}$ \\
\hline \#2. & 41.4 & $\begin{array}{l}\text { BRCA1 } \\
\text { c.3746dupA }\end{array}$ & $0 /$ No & No & Sister & No & No & $\begin{array}{l}\text { Surveillance } \\
\diamond \text { RRSO }\end{array}$ & 69.0 & $\begin{array}{l}\text { Newly } \\
\text { diagnosed } \\
\text { BC; } \\
\text { Normal } \\
\text { uterus and } \\
\text { ovaries }\end{array}$ & $\begin{array}{l}\text { SPL } \\
\text { BSO } \\
\text { and BC } \\
\text { surgery }\end{array}$ \\
\hline \#3. & 70.2 & $\begin{array}{l}\text { BRCA2 } \\
\text { c.3744_3747delTGAG }\end{array}$ & $2 / \mathrm{MP}$ & HTN & Sister & No & $\begin{array}{l}\text { Yes } \\
(70.2)\end{array}$ & $\begin{array}{l}\text { Surveillance } \\
\diamond \text { RRSO }\end{array}$ & 14.3 & $\begin{array}{l}\text { Bilateral } \\
\text { ovarian } \\
\text { cysts }\end{array}$ & $\begin{array}{l}\text { SPL } \\
\text { BSO }\end{array}$ \\
\hline \#4. & 54.8 & $\begin{array}{l}B R C A 2 \\
\text { c. } 1399 A>T\end{array}$ & $2 / \mathrm{MP}$ & HTN & $\begin{array}{l}\text { Mother, } \\
\text { Sister } \\
2\end{array}$ & No & $\begin{array}{l}\text { Yes } \\
(47.7)\end{array}$ & Surveillance & 103.8 & $\begin{array}{l}\text { Development o } \\
\text { peritoneal } \\
\text { carcinomatosi } \\
\text { ascites }\end{array}$ & and \\
\hline \#5. & 47.7 & $\begin{array}{l}\text { BRCA1 } \\
\text { c.911_918dupTCTGTAAT }\end{array}$ & $2 /$ No & DM & Mother & Mother & $\begin{array}{l}\text { Yes } \\
(47.7)\end{array}$ & Surveillance & 26.3 & $\begin{array}{l}\text { LEEP due to } P \\
\text { abnormality }(A\end{array}$ & SC-H) \\
\hline
\end{tabular}

Abbreviations: ASC-H, atypical squamous cells cannot exclude HSIL; BC, breast cancer; BSO, bilateral salpingo-oophorectomy; DM, diabetes; FIGO, Internation Gynaecology and Obstetrics; HGSC, high-grade serous carcinoma; HTN, hypertension; MP, menopause; OC, ovarian cancer; RH, radical hysterectomy; RRSO, ri: oophorectomy; SCC, squamous cell carcinoma; SPL, single-port laparoscopy.

Lastly, we re-assigned the study population to the RRSO strategy and surveillance strategy groups based on the women's age at the time of the BRCA1/2 gene test and time interval between the test and actual date of RRSO (12 months). After excluding 14 women aged $<35$ years, we identified that 44 of the 103 women received RRSO within 12 months after genetic testing; therefore, the intentional uptake rate of RRSO was $42.7 \%$. Multivariate analysis was conducted to identify the factors affecting the BRCA1/2 mutation carrier's decision on taking RRSO strategy rather than surveillance. Results showed that an age of $\geq 50$ years (aOR, 5.060; 95\% Cl, 1.639-15.623; $P=0.005)$ and employed status (aOR, 3.402; 95\% Cl, $1.104-10.484 ; P=0.033$ ) were positive factors towards RRSO strategy (Table 4).

Table 4

Factors associated with taking risk-reducing salpingo-oophorectomy strategy rather than surveillance

\begin{tabular}{|c|c|c|c|c|c|c|c|}
\hline \multirow[t]{2}{*}{ Characteristics } & \multirow[t]{2}{*}{ Comparison } & \multicolumn{3}{|c|}{ Univariate analysis } & \multicolumn{3}{|c|}{ Multivariate analysis } \\
\hline & & OR & $95 \% \mathrm{Cl}$ & $P$ & aOR & $95 \% \mathrm{Cl}$ & $P$ \\
\hline Age at $B R C A$ test, years & $\geq 50$ vs. $<50$ & 2.770 & $1.234-6.219$ & 0.014 & 5.060 & $1.639-15.623$ & 0.005 \\
\hline Menopausal status* & Menopause vs. Premenopause & 1.964 & $0.889-4.339$ & 0.095 & & & \\
\hline Parity & Parous vs. Null & 1.346 & $0.368-4.919$ & 0.653 & & & \\
\hline Educational status & $\geq$ College vs. $\leq$ High school & 0.711 & $0.292-1.727$ & 0.451 & 0.735 & $0.238-2.270$ & 0.593 \\
\hline Occupational status & Yes vs. No & 2.677 & $1.153-6.216$ & 0.022 & 3.402 & $1.104-10.484$ & 0.033 \\
\hline Prior abdominopelvic surgery & Yes vs. No & 0.936 & $0.415-2.125$ & 0.874 & & & \\
\hline Family $\mathrm{Hx}$ of breast cancer ${ }^{\dagger}$ & Yes vs. No & 1.041 & $0.463-2.338$ & 0.923 & & & \\
\hline Family $\mathrm{Hx}$ of ovarian cancer ${ }^{\dagger}$ & Yes vs. No & 1.469 & $0.587-3.677$ & 0.412 & 1.948 & $0.596-6.367$ & 0.270 \\
\hline Mutated gene & $B R C A 1$ vs. $B R C A 2$ & 0.753 & $0.344-1.647$ & 0.477 & & & \\
\hline \multicolumn{8}{|c|}{ Abbreviations: $\mathrm{Hx}$, history; OR, odds ratio; aOR, adjusted OR; Cl, confidence interval. } \\
\hline
\end{tabular}

\section{Discussion}

In this retrospective cohort study, we presented our real-world experience on management of female germline $B R C A 1 / 2$ mutation carriers in relation to RRSO strategy. The total and intentional uptake rates of RRSO were $70.1 \%$ and $42.7 \%$, respectively. Despite RRSO, incidental ovarian/tubal cancers were identified in $3.7 \%$ of the women. BRCA1/2 mutation carriers' age and occupational status affected their decision on taking RRSO strategy rather than surveillance. 
The ovary is an essential organ for maintaining fertility and secreting female sex hormones, especially estrogen. Therefore, women with premature surgical menopause may suffer from an increased risk of bone loss, cardiovascular disease, and decreased cognitive function (7). In addition, they may experience a lower quality of life due to vasomotor symptoms, such as hot flashes, sweating, etc. Moreover, women who experience early menopause may feel that they have lost their femininity. In this aspect, older women, particularly those who have already experienced menopause, are more inclined to undergo RRSO, compared to young, premenopausal women (8).

Women who are employed also tended to choose RRSO strategy, rather than surveillance, possibly because it is more difficult for them to take regular screening tests, compared with unemployed women. Previous studies have shown that family history of cancer and personal history of breast cancer were important factors for $B R C A 1 / 2$ mutation carriers to undergo RRSO $(9,10)$. In addition, the type of mutated $B R C A$ gene and menopausal status were significantly associated with RRSO (11). However, we observed inconsistent results, which might originate from the uniqueness of our study population; $86.3 \%$ of the mutation carriers had been diagnosed with breast cancer before genetic testing in this study. In general, people who have no personal cancer history are known to be reluctant to undergo $B R C A 1 / 2$ gene testing, even if they have high-risk factors such as a family history of cancer.

The total uptake rate of RRSO in this study was at the upper end of the range described in previous studies, who reported it as $50-70 \%$ with inter-center and inter-country variations (11-13). These variations are due to differences in the characteristics of the study population, sociocultural atmosphere, follow-up period, follow-up strategy, counselling by gynecologists, and so on. In Korea, the tendency to receive RRSO is highly influenced by the policy of the National Health Insurance Service (NHIS). The NHIS started to cover the BRCA1/2 gene test in epithelial ovarian and breast cancer patients with a family history of cancer in April 2012, and RRSO in BRCA1/2 mutated cancer patients in December 2012. Thereafter, the annual number of female cancer patients undergoing $B R C A 1 / 2$ gene testing and RRSO increased rapidly. Furthermore, in 2017, the NHIS began to cover the BRCA1/2 gene test not only for ovarian and breast cancer patients but also for first-degree families of BRCA-mutated cancer patients.

The intentional uptake rate of RRSO was only $42.7 \%$, which was quite low. We could infer that about half of the patients in the RRSO group wanted to take intensive screening at first, considering the finding that $3.7 \%$ of women in the RRSO group were incidentally diagnosed with ovarian/tubal cancers despite no abnormal findings on preoperative evaluation. In literature, the occult ovarian/tubal cancer rate in BRCA1/2 mutation carriers undergoing RRSO was described as $0.6-17 \%(14-18)$. Therefore, it is recommended that BRCA1/2 mutation carriers, especially those who completed childbearing, undergo RRSO soon after genetic testing to prevent development of ovarian/tubal cancer and microscopic cancer progression. Nevertheless, neglecting cancer screening after RRSO should be avoided, as risks of developing primary peritoneal cancer and breast cancer still remain (19).

With accumulated evidence that the fallopian tube plays a principal role in the development of ovarian/tubal cancer, some researchers have proposed a riskreducing early salpingectomy and delayed oophorectomy (RRESDO) strategy for premenopausal women to resolve problems with premature menopause (20, 21). RRESDO is a two-stage surgical alternative to RRSO. In a pilot study, early salpingectomy was done for premenopausal women just after detection of a $B R C A 1 / 2$ gene mutation. Then, delayed oophorectomy was recommended for patients at age 40 with the $B R C A 1$ gene mutation and age 45 with the $B R C A 2$ gene mutation (22). Most patients who underwent RRESDO, particularly women concerned about sexual dysfunction, were satisfied with their choice of surgery. However, the RRESDO strategy still remains investigational and a clinical trial is required to make this strategy routine (23).

For BRCA1/2 mutation carriers who are reluctant to undergo RRSO, the Korean Society of Gynecologic Oncology (KSOG) recommends transvaginal sonography or serum CA-125 tests every 4 months (24). Such intense screening might offer a better chance for early detection of ovarian cancer, however, robust scientific evidence on this issue is needed.

The current study had several limitations. First, there was bias in the study population towards breast cancer patients. Second, not all possible confounding factors were included. In particular, the causes of amenorrhea, such as natural menopause, surgical menopause, and medication-induced menopause (e.g., tamoxifen, aromatase inhibitor), were not considered. Third, the trend of undergoing RRSO with time was not analyzed. Further prospective cohort studies are warranted in a larger population.

In conclusion, the total uptake rate of RRSO in female germline BRCA1/2 mutation carriers was $70.1 \%$, but the intentional uptake rate was much lower at $42.7 \%$. The uptake rate of RRSO was affected by the carriers' age and occupational status. Considering the $3.7 \%$ of incidental cancer cases in women who underwent RRSO despite no abnormal findings on preoperative evaluation, it is recommended to perform RRSO soon after the confirmation of germline BRCA1/2 mutations.

\section{Abbreviations}

aOR, adjusted odds ratio; $\mathrm{Cl}$, confidence interval; HGSC, high-grade serous carcinoma; KSOG, Korean Society of Gynecologic Oncology; NGS, next-generation sequencing; NHIS, National Health Insurance Service; RRESDO, risk-reducing early salpingectomy and delayed oophorectomy; RRM, risk-reducing mastectomy; RRSO, risk-reducing salpingo-oophorectomy; SNUH, Seoul National University Hospital

\section{Declarations}

\section{ACKNOWLEDGMENTS}

Not applicable

\section{ETHICS APPROVAL AND CONSENT TO PARTICIPATE}


This retrospective cohort study was approved by the Institutional Review Board of Seoul National University Hospital (SNUH; No. H-2011-040-1170) and conducted in accordance with the principles of the Declaration of Helsinki. The requirement for informed consent was waived.

\section{AUTHORS' CONTRIBUTIONS}

ML and SIK conceived the concept for the manuscript. SH and GBL collected the data. HL wrote the initial draft of the manuscript. All authors contributed to edit the manuscript. All authors read and approved the final manuscript.

\section{FUNDING}

This work was supported by grants from the Seoul National University Hospital Research Fund (No. 0320190260) and the National Research Foundation of Korea (NRF), funded by the Ministry of Science and ICT (No. 2020R1G1A1005711).

\section{AVAILABILITY OF DATA AND MATERIALS}

Not applicable

\section{CONSENT FOR PUBLICATION}

The requirement for informed consent was waived

\section{COMPETING INTERESTS}

The authors declare no conflicts of interest relevant to this study.

\section{References}

1. Sung H, Ferlay J, Siegel RL, Laversanne M, Soerjomataram I, Jemal A, et al. Global cancer statistics 2020: GLOBOCAN estimates of incidence and mortality worldwide for 36 cancers in 185 countries. CA Cancer J Clin. 2021.

2. Practice Bulletin No 182. Hereditary Breast and Ovarian Cancer Syndrome. Obstet Gynecol. 2017;130(3):e110-e26.

3. Menon U, Karpinskyj C, Gentry-Maharaj A. Ovarian Cancer Prevention and Screening. Obstet Gynecol. 2018;131(5):909-27.

4. Antoniou A, Pharoah PD, Narod S, Risch HA, Eyfjord JE, Hopper JL, et al. Average risks of breast and ovarian cancer associated with BRCA1 or BRCA2 mutations detected in case Series unselected for family history: a combined analysis of 22 studies. Am J Hum Genet. 2003;72(5):1117-30.

5. Daly MB, Pilarski R, Yurgelun MB, Berry MP, Buys SS, Dickson P, et al. NCCN guidelines insights: genetic/familial high-risk assessment: breast, ovarian, and pancreatic, version 1.2020: featured updates to the NCCN guidelines. J Natl Compr Canc Netw. 2020;18(4):380-91.

6. Kim SI, Lee M, Kim HS, Chung HH, Kim JW, Park NH, et al. Effect of BRCA mutational status on survival outcome in advanced-stage high-grade serous ovarian cancer. J Ovarian Res. 2019;12(1):40.

7. Gordhandas S, Norquist BM, Pennington KP, Yung RL, Laya MB, Swisher EM. Hormone replacement therapy after risk reducing salpingo-oophorectomy in patients with BRCA1 or BRCA2 mutations; a systematic review of risks and benefits. Gynecol Oncol. 2019;153(1):192-200.

8. Miller SM, Roussi P, Daly MB, Scarpato J. New strategies in ovarian cancer: uptake and experience of women at high risk of ovarian cancer who are considering risk-reducing salpingo-oophorectomy. Clin Cancer Res. 2010;16(21):5094-106.

9. Bradbury AR, Ibe CN, Dignam JJ, Cummings SA, Verp M, White MA, et al. Uptake and timing of bilateral prophylactic salpingo-oophorectomy among BRCA1 and BRCA2 mutation carriers. Genet Med. 2008;10(3):161-6.

10. Metcalfe KA, Foulkes WD, Kim-Sing C, Ainsworth P, Rosen B, Armel S, et al. Family history as a predictor of uptake of cancer preventive procedures by women with a BRCA1 or BRCA2 mutation. Clin Genet. 2008;73(5):474-9.

11. Kim SI, Lim MC, Lee DO, Kong SY, Seo SS, Kang S, et al. Uptake of risk-reducing salpingo-oophorectomy among female BRCA mutation carriers: experience at the National Cancer Center of Korea. J Cancer Res Clin Oncol. 2016;142(1):333-40.

12. Sidon L, Ingham S, Clancy T, Clayton R, Clarke A, Jones EA, et al. Uptake of risk-reducing salpingo-oophorectomy in women carrying a BRCA1 or BRCA2 mutation: evidence for lower uptake in women affected by breast cancer and older women. Br J Cancer. 2012;106(4):775-9.

13. Chai X, Friebel TM, Singer CF, Evans DG, Lynch HT, Isaacs C, et al. Use of risk-reducing surgeries in a prospective cohort of 1,499 BRCA1 and BRCA2 mutation carriers. Breast Cancer Res Treat. 2014;148(2):397-406.

14. Piedimonte S, Frank C, Laprise C, Quaiattini A, Gotlieb WH. Occult Tubal Carcinoma After Risk-Reducing Salpingo-oophorectomy: A Systematic Review. Obstet Gynecol. 2020;135(3):498-508.

15. Palaiologos K, Ellaboudy A, Abdullah M, Karan S, Saha A. Prophylactic Bilateral Salpingo-oophorectomy in BRCA2 Mutation with Incidental Finding of Serous Tubal Intraepithelial Carcinoma (STIC) and Subsequent Diagnosis of Primary Peritoneal Carcinoma (PPC): A Case Report and Review of Current Literature. Cureus. 2020;12(7):e9301.

16. Colgan TJ, Murphy J, Cole DE, Narod S, Rosen B. Occult carcinoma in prophylactic oophorectomy specimens: prevalence and association with BRCA germline mutation status. Am J Surg Pathol. 2001;25(10):1283-9.

17. Agoff SN, Garcia RL, Goff B, Swisher E. Follow-up of in situ and early-stage fallopian tube carcinoma in patients undergoing prophylactic surgery for proven or suspected BRCA-1 or BRCA-2 mutations. Am J Surg Pathol. 2004;28(8):1112-4. 
18. Vaughan MH, Modesitt SC, Mo Y, Trowbridge ER. Serous tubal intraepithelial carcinoma: an incidental finding at the time of prophylactic bilateral salpingo-oophorectomy. Case Rep Obstet Gynecol. 2015;2015:760429.

19. Mavaddat N, Antoniou AC, Mooij TM, Hooning MJ, Heemskerk-Gerritsen BA, Genepso, et al. Risk-reducing salpingo-oophorectomy, natural menopause, and breast cancer risk: an international prospective cohort of BRCA1 and BRCA2 mutation carriers. Breast Cancer Res. 2020;22(1):8.

20. Gaba F, Blyuss O, Chandrasekaran D, Osman M, Goyal S, Gan C, et al. Attitudes towards risk-reducing early salpingectomy with delayed oophorectomy for ovarian cancer prevention: a cohort study. BJOG. 2021;128(4):714-26.

21. Ghezelayagh TS, Stewart LE, Norquist BM, Bowen DJ, Yu V, Agnew KJ, et al. Perceptions of risk and reward in BRCA1 and BRCA2 mutation carriers choosing salpingectomy for ovarian cancer prevention. Fam Cancer. 2020;19(2):143-51.

22. Nebgen DR, Hurteau J, Holman LL, Bradford A, Munsell MF, Soletsky BR, et al. Bilateral salpingectomy with delayed oophorectomy for ovarian cancer risk reduction: A pilot study in women with BRCA1/2 mutations. Gynecol Oncol. 2018;150(1):79-84.

23. Gaba F, Piek J, Menon U, Manchanda R. Risk-reducing early salpingectomy and delayed oophorectomy as a two-staged alternative for primary prevention of ovarian cancer in women at increased risk: a commentary. BJOG. 2019;126(7):831-9.

24. Choi MC, Lim MC, Suh DH, Song YJ, Kim TJ, Chang SJ, et al. Position statements on genetic test for peritoneal, ovarian, and fallopian tubal cancers: Korean Society of Gynecologic Oncology (KSGO). J Gynecol Oncol. 2016;27(4):e36.

\section{Figures}

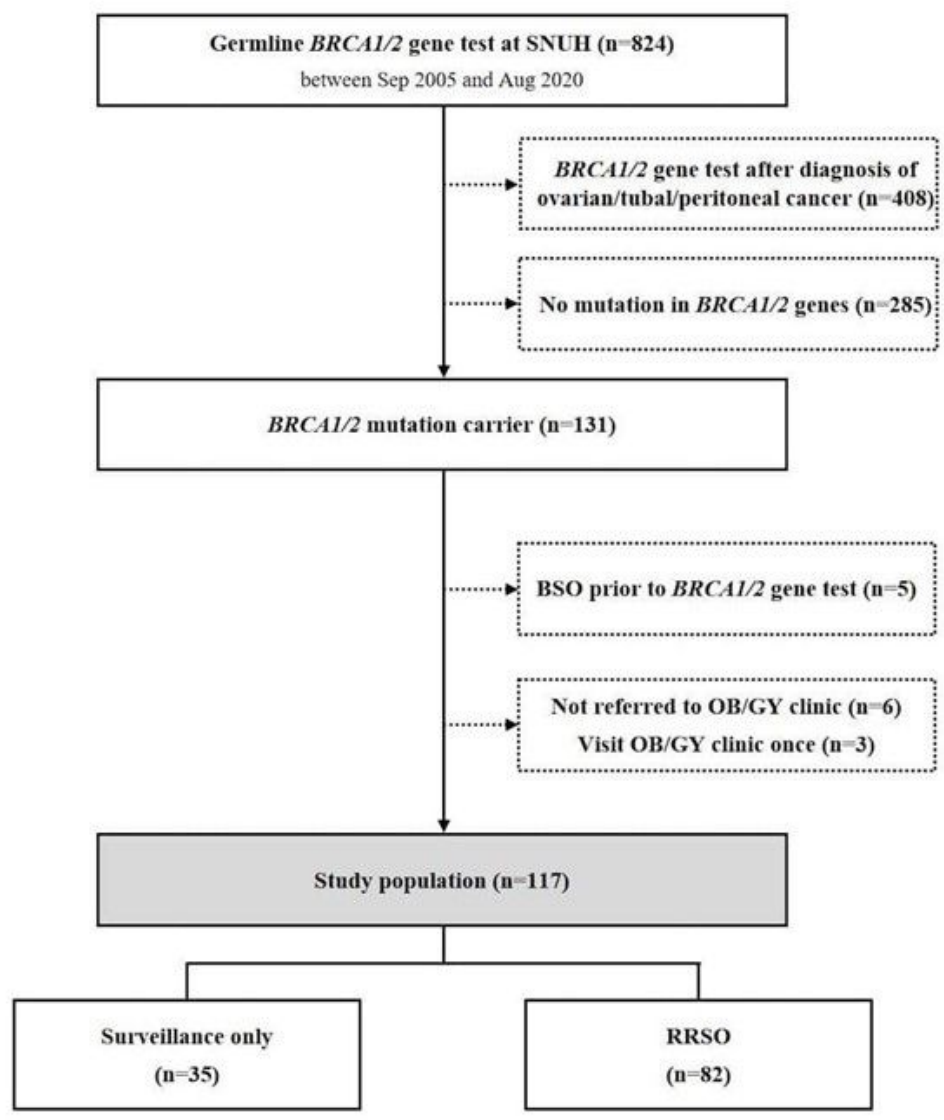

Figure 1

A flow diagram depicting the selection of the study population. 


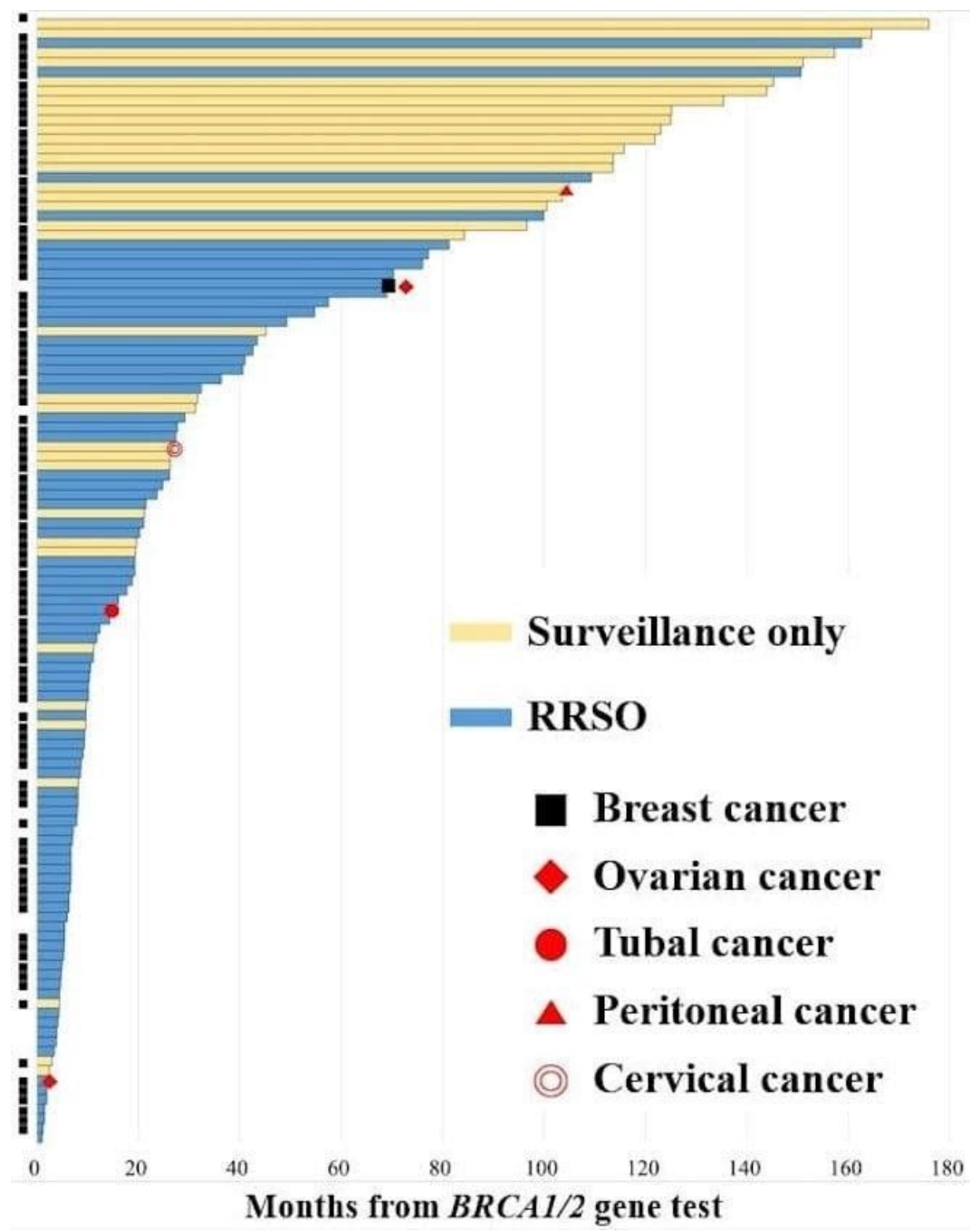

Figure 2

Follow-up of study population after the BRCA1/2 gene test.

\section{Supplementary Files}

This is a list of supplementary files associated with this preprint. Click to download.

- SupplementaryTable1.docx

- SupplementaryTable2.docx 